BULLETIN Bulletin hispanique

HISPANIQUE Université Michel de Montaigne Bordeaux

$113-2$ | 2011

Varia

\title{
Juan José Domenchina, Artículos selectos
}

Fundación Banco de Santander, Madrid, 2010

Jacques Issorel

\section{OpenEdition}

Journals

Édition électronique

URL : http://journals.openedition.org/bulletinhispanique/1475

DOI : 10.4000/bulletinhispanique. 1475

ISSN : $1775-3821$

Éditeur

Presses universitaires de Bordeaux

\section{Édition imprimée}

Date de publication : 1 décembre 2011

Pagination : 803-805

ISBN : 978-2-86781-793-9

ISSN : 0007-4640

Référence électronique

Jacques Issorel, « Juan José Domenchina, Artículos selectos », Bulletin hispanique [En ligne], 113-2 |

2011, mis en ligne le 05 avril 2013, consulté le 23 septembre 2020. URL : http://

journals.openedition.org/bulletinhispanique/1475; DOI : https://doi.org/10.4000/bulletinhispanique. 1475 
Tampoco de que sus planteamientos responden ya a un contexto muy distinto que aquel en que se movían sus antecesores. Poco importa que se proclame « declamador " que no historiador, si su propósito fue « entender la forma que puede recibir nuestra historia para que sea útil no solo a los ciudadanos, pero principalmente a los monarcas y a los hombres públicos ${ }^{10}$ ". Declaración de intenciones que reúne ejemplarmente todos los topos de un ilustrado, más inclinado a actuar en lo concreto que en hacer «invenciones quiméricas ${ }^{11}$ ». Personaje peculiar este Juan Pablo Forner al que el prof. Lopez ha vuelto a rescató, no ya del cajón de los reaccionarios españoles, sino del olvido, haciendo valer su esfuerzo por apuntalar su fama con la defensa del honor patrio.

Como escrito por un gran conocedor de la intrahistoria de los libros, el estudio aborda también las variaciones entre los distintos manuscritos que de la obra se conservan, señalando algunas de sus variaciones. Tanto la modernización de la ortografía y de la puntuación, así como las correcciones de las erratas, ya realizadas para la edición de 1973, han sido ahora cuidadosamente revisadas. Igualmente se han enriquecido las notas con datos que entonces faltaban y se han introducido otras nuevas, así como un índice onomástico, tarea realizada con la colaboración de Juan López Tabar. El resultado de todo ello es una edición manejable y cuidada que merece tenerse en cuenta. Con ella se despide François Lopez de Forner y de todos nosotros, dando un vez más muestra de su rigor intelectual y de su lúcida mirada sobre el pasado.

\section{Victoria LÓPEZ-CORDÓN CORTEZO}

Juan José Domenchina, Artículos selectos, prólogo y compilación de Amelia de Paz, Madrid, Fundación Banco de Santander, 2010, XXXVIII + 446 p. (col. Obra Fundamental).

En publiant en 1995 l'œuvre poétique complète de Juan José Domenchina (Obra poética, Madrid, Castalia-Comunidad de Madrid), dix ans plus tard "Cuarenta poemas inéditos de Juan José Domenchina» (Nueva Revista de Filología Hispánica, t. 53, n 1, 2005, pp. 129-162) et, en 2008, une édition critique des Tres elegías jubilares (Madrid, Cátedra), Amelia de Paz a donné

10. Ibidem, p. 6.

11. P. LXXXV. 
une deuxième jeunesse à des textes jusque-là difficilement accessibles ${ }^{12}$. Elle poursuit aujourd'hui cette tâche en publiant 90 (sur plus de 400) des articles de critique littéraire que, d'abord sous le pseudonyme de Gerardo Rivera, ensuite sous son patronyme, Domenchina fit paraitre dans la presse madrilène de 1931 à 1936, puis dans des revues et des journaux mexicains de 1940 à 1959, année de sa mort en exil.

Comme l'explique l'éditrice dans "Criterios de edición ", ces articles concernent la littérature espagnole - surtout la poésie contemporaine -, les littératures européennes - particulièrement la production française -, et la littérature hispano-américaine, avec une nette prédominance de la poésie et du roman mexicains. Quatre articles, enfin, relèvent de la " especulación teórica" (p. XXVI). C'est dans l'un d'eux que l'on trouve la formule qui pourrait servir d'épigraphe à toute l'œuvre critique de Domenchina : "Para mí no existen autores, sino libros » («El dolor de la crítica », p. 73). Gerardo Rivera, dont les critiques acérées valurent à leur auteur de durables inimitiés, se plaint ailleurs de " la falta de comentadores íntegros " et du trop-plein de "glosadores circunstanciales y oficiosos " ( Un monólogo dialogado ", p. 303), allant même jusqu’à affirmer que « la crítica, en España, por lo que a las letras se refiere, es una simple abstracción: una sede vacante. No existe " ("El cotarro crítico », p. 91). Aussi Domenchina se sent-il, dès ses premiers articles, investi d'une mission : «Ser [...] el cedazo que separe la harina del salvado ", comme l'écrit Amelia de Paz dans son prologue (p. XIII).

Si Pío Baroja (" un talento de tercer orden ", p. 89), Pedro Salinas (" los glaciales madrigales psicotécnicos del autor de Visperas del gozo", p. 159), José Bergamín (" el prototipo del parodista [...] que no "hace", sino que "rehace" ", p. 83) et même Jorge Guillén ("suele [...] desmesurar artificialmente el volumen de las cosas tratando de magnificarlas », p. 47) ne trouvent pas grâce à ses yeux, en revanche, il se plaît à décrire, avec talent et dans une belle et riche langue, les qualités de Gabriel Miró ("Con un libro de Miró en la mano, el lector siente la vida torrencial y sincrónicamente con todos los sentidos », p. 77), de Vicente Aleixandre (" una arrebatadora lección de belleza », p. 201), de Rafael Alberti ("la voz dicharachera [...] pero siempre vital y nunca docente, del joven lírico andaluz », p. 159), de Miguel Hernández qui, dit-il, réussit à concilier "puericia ", " primicia " et «pericia » (p. 269), et de Federico García Lorca (" el único poeta joven auténticamente popular », p. 239). Ses articles sur Azorín, Unamuno, ValleInclán, Juan Ramón Jiménez, Ortega y Gasset, Rómulo Gallegos, mais aussi

12. Voir Bulletin hispanique, XCVIII, n 1, 1996, p. 235-238 et ibid., III, n 1, 2009, pp. 286-288. 
ceux consacrés à Balzac, Stendhal, Proust, Valéry, sont d'une telle profondeur que presque un siècle après avoir été écrits, ils continuent d'être une précieuse introduction à l'œuvre de ces divers écrivains. Tout aussi perspicaces sont les quatre articles que Domenchina consacra à Antonio Machado. On ne les trouvera pas ici mais réunis par Amelia de Paz dans Semblanzas machadianas (Santander, La Sirena del Pisueña, col. 22 de febrero, 2009, 59 p.). Certaines appréciations de Juan José Domenchina ont, toutefois, mal résisté à l'épreuve du temps. Aux œuvres de Ramón Pérez de Ayala - à qui il promet le Prix Nobel -, de Feliciano Rolán ou de Enrique Díez-Canedo, la postérité est loin d'avoir accordé le même et généreux crédit que, en son temps, Juan José Domenchina.

Amelia de Paz intitule son prologue "Epitafio de Domenchina» (p. XIXXV). Dans ce texte où elle allie avec bonheur rigueur scientifique et qualité d'écriture, elle décrit l'itinéraire de Domenchina, de l'adolescence à la fin désespérée dans un México où il se sentit toujours étranger. À l'instar de Domenchina, elle possède le sens de la formule et termine par ces mots : "Fue corajudo y bueno, lo leyó todo, murió de España. Descanse en paz, Domenchina ».

Jacques ISSOREL

Gerardo Diego, Fábula de Equis y Zeda, México, Alcancía, 1932 [fac-similé de la première édition], Santander, Fundación Gerardo Diego, 2010, $27 \mathrm{p}$.

Juan Manuel Díaz de Guereñu, Fábula del explorador y el catedrático, Santander, Cuadernos adrede, $\mathrm{n}^{\circ}$ 6, 2010, 93 p.

Ces deux volumes se présentent ensemble dans une même pochette en papier kraft sur laquelle est reproduite la couverture de l'édition mexicaine de 1932. Díaz de Guereñu retrace le curieux destin éditorial que connut cette œuvre de Gerardo Diego. D'abord publiée partiellement en 1927 et 1930 dans Litoral (Málaga) et dans la Revista de Santander, puis en édition intégrale dans la revue mexicaine Contemporáneos (1930), elle fit l'objet, deux ans plus tard et toujours au Mexique, d'une édition pirate, mais non vénale, que le poète, d'abord surpris, ne tarda pas à approuver et dont il remercia les auteurs. C'est le fac-similé de cette édition, accompagné d'une étude de ce long poème de 246 vers, que nous offre Díaz de Guereñu. Comme nombre d'œuvres de Diego, celle-ci est placée sous le double signe de la tradition et de la nouveauté. Chacune des 41 strophes est une illustration 